doi http://dx.doi.org/10.18542/mri.v14i23.9531

\title{
RECURSOS DIDÁTICOS E INCLUSIVOS PARA O ENSINO DO MEIO AMBIENTE
} TEACHING AND INCLUSIVE RESOURCES FOR ENVIRONMENTAL EDUCATION

\author{
Kauê Felippe de MORAES ${ }^{1}$ \\ Universidade Federal do Pará (UEPA) \\ Bruna Rafaela Mendonça OLIVEIRA ${ }^{2}$ \\ Universidade do Estado do Pará (UEPA) \\ Luciana de Nazaré FARIAS ${ }^{3}$ \\ Universidade do Estado do Pará (UEPA)
}

Resumo: Este artigo refere-se à utilização de recursos didáticos e inclusivos para o ensino de Meio Ambiente, experiência realizada em uma turma de discentes do PARFOR que atuam no Ensino Fundamental com a disciplina Biologia. Tem por objetivo analisar as dificuldades enfrentadas por esses professores em formação que atuam com alunos com deficiência visual (cegos/baixa visão). A metodologia com base na pesquisa qualitativa, se deu em três diferentes etapas e culminou com a realização do workshop intitulado de "Recursos Didáticos e Inclusivos para o Ensino de Meio Ambiente", onde foi construído e experimentado o uso de um "Dominó Inclusivo Sobre Meio Ambiente". Os resultados apontam que os acadêmicos apresentam experiências na educação dos alunos deficientes visuais. Porém, ainda há dificuldades em promover a educação inclusiva no ensino regular.

Palavras-chave: Deficiência Visual, Educação Inclusiva, Meio Ambiente, Recursos Didáticos.

\begin{abstract}
This article refers to the use of didactic and inclusive resources for the teaching of Environment, experience carried out in a class of PARFOR students who work in Primary Education with the discipline Biology. It aims to analyze the difficulties faced by these teachers who work with visually impaired students (blind/low vision). The methodology, based on qualitative research, took place in three different stages and culminated in the workshop entitled "Didactic and Inclusive Resources for Teaching the Environment", where the use of an "Inclusive Domino over the Environment" was built and experimented. The results show that the academics present experiences in the education of visually impaired students. However, there are still difficulties in promoting inclusive education in regular education.
\end{abstract}

Keywords: Visual Impairment, Inclusive Education, Environment, Didactic Resources.

\footnotetext{
${ }^{1}$ Graduação em Licenciatura Plena Em Ciências Naturais - Biologia (Universidade do Estado do Pará), Mestrado em Ecologia pelo Programa de Pós-graduação em Ecologia (UFPA/EMBRAPA), e doutorando em Zoologia pelo programa de Pós-graduação em Zoologia (UFPA/MPEG).E-mail: kaauemoraes @yahoo.com.br

${ }^{2}$ Graduação em Licenciatura Plena Em Ciências Naturais - Biologia pela Universidade do Estado do Pará. E-mail: bruunaa.rafa@hotmail.com

${ }^{3}$ Graduação em Licenciatura Plena Em Ciências Biológicas pela Universidade Federal do Pará, Mestrado e Doutorado em Educação em Ciências e Matemáticas pela Universidade Federal do Pará. Docente na Universidade do Estado do Pará.. Email: lubiologia2003@yahoo.com.br
} 


\section{INTRODUÇÃO}

Diversas pesquisas da área de Educação em Ciências defendem a necessidade de reformulação e inovação das práticas docentes (GEHLEN, AUTH E AULER, 2008; AULER, 2007; MALDANER E ZANON, 2004; GONÇALVES, 2000; MONIZ DOS SANTOS, 1999) no contexto de superação do modo tradicional e ultrapassado de "passar" conteúdos puramente informativos, propedêuticos de modo decorativo, fragmentados, descontextualizados e excludentes nas aulas de ciências (MALDANER E ZANON, 2004). Onde a ciência é abordada de forma meramente ilustrativa, dissociadas das discussões e do contexto atual, no qual os meios tecnológicos e digitais, bem como novas metodologias e recursos didáticos podem e devem promover a inclusão de todos os alunos.

Desse modo, é necessário renovação e inclusão no ensino de ciências, de modo que o ensino promova a alfabetização científica, buscando avançar no sentido da concepção de ciências e seu processo de ensino-aprendizagem, concernentes com o século XXI (FARIAS; MIRANDA; FILHO, 2012).

$\mathrm{O}$ aluno deficiente visual ${ }^{4}$ (DV) precisa de incentivo para que possa ser sujeito ativo no ambiente escolar para assim construir os conhecimentos necessários à sua formação, deste modo os alunos DV, obterão educação escolar de qualidade. Diante disso, o intuito principal do trabalho, é investigar as concepções dos estudantes de Licenciatura da área de Ciências Naturais - Habilitação em Biologia do Plano Nacional de Formação de Professores (PARFOR) sobre a formação de professores de Biologia para atuar com alunos DV com a utilização de recursos didáticos e inclusivos para o ensino de meio ambiente.

\section{OS ESTUDOS ECOLÓGICOS E O MEIO AMBIENTE: ELEMENTOS PARA UMA EDUCAÇÃO INCLUSIVA}

A palavra Ecologia foi criada por Ernest Haeckel e usada pela primeira vez no ano de 1869. Segundo Peroni e Hernández (2011, p.11), Haeckel definiu a Ecologia como "o estudo científico das interações entre os organismos e seu ambiente". E após isso, em 1972, C. J. Krebs aprofundou a definição de Ecologia como "o estudo científico das interações que determinam a distribuição e abundância dos organismos”. Tal definição enfatiza que as interações são fatores determinantes para a distribuição e abundância dos seres vivos e faz uso de previsões testáveis e análises estatísticas,

\footnotetext{
${ }^{4} \mathrm{O}$ termo deficiência visual não significa, necessariamente, total incapacidade para ver. Na verdade, sob deficiência visual poderemos encontrar pessoas com vários graus de visão residual.

(http://www.ce.ufpb.br/nedesp/contents/noticias/deficiencia-visual-a-cegueira-e-a-baixa-visao).
} 
possibilitando a individualização da Ecologia enquanto ciência e a diferenciando-a da História Natural (KREBS, 2006; MENEZES; MARTINS; ARAÚJO, 2016).

A ecologia aborda todos os assuntos relacionados à biodiversidade e meio ambiente. Ela explica desde a criação de um meio natural e seu clímax, até as relações dos animais que participam desse meio. Dessa forma, este caracteriza como um elemento despertador do senso crítico dos discentes acerca do ambiente na qual ele está inserido. $\mathrm{O}$ autor Mariani Junior concorda com este argumento, ao afirmar que:

As informações, o conhecimento adquirido, as competências e habilidades desenvolvidas na escola devem se reverter em ações que promovam a satisfação, o bem-estar social e, sobretudo, a preocupação constante com as futuras gerações, ou seja, promover ações que visem à menor degradação do meio com a possibilidade de usufruto dos recursos naturais para as gerações futuras. (2008, p.17).

Beltramin e Góis (2009) afirmam que a instituição escolar tem um papel fundamental na formação do cidadão, pois o acesso ao conhecimento científico pode inserir o aluno em questões fundamentais que possam contribuir para o avanço da sociedade.

Nesse contexto, é crucial uma formação qualificada dos professores, em que se busquem metodologias que torne o ensino/aprendizagem acessível aos discentes. Apesar da importância de abordar este assunto em sala, o conteúdo apresenta grandes dificuldades para a compreensão dos discentes. Entre os fatores que caracterizam esta dificuldade, destacam-se os termos presentes no conteúdo, os mecanismos que são apenas apresentados sem contextualização e a falta de recursos didáticos que busquem o interesse e a atenção dos alunos.

No que tange ao ensino de ciências, (FARIAS, 2017) destaca que é urgente e necessário que os cursos que formam professores para atuar na educação básica, possibilitem em sua formação inicial o desenvolvimento, reflexão e ação sobre o ensino de ciências. Evidenciando a sua importância para a formação integral e o exercício da cidadania, não se limitando a disciplinas de cunho muitas vezes eminentemente teóricos e desvinculados da realidade e contexto dos alunos.

Diante destes problemas elencados, é necessário que o professor busque alternativas que possibilitem ao aluno uma formação de qualidade sobre os diversos assuntos abordados no contexto escolar. Dessa forma, os recursos didáticos se apresentam como uma das alternativas para auxiliar no processo de ensino aprendizagem dos alunos.

Segundo Castoldi (2016), as utilizações de recursos didático-pedagógicos são alternativas válidas para preencher as lacunas existentes no ensino tradicional, e enquanto o conteúdo é 
apresentado aos alunos, é possível mantê-los como participantes do processo de aprendizagem durante o momento em que está sendo usado o recurso.

Como afirma Souza (2007), recurso didático é todo e qualquer material utilizado que seja relevante para o processo de ensino aprendizagem do aluno. Ou seja, filmes, jogos, músicas e outros instrumentos de interação e entretenimento, podem ser considerados recursos, a partir do momento em que são direcionados ao ensino.

Os benefícios de usar práticas inovadoras de ensino no tripé educacional (professor - aluno conhecimento) são infinitos. Para o aluno, alguns recursos podem ter papel fundamental na retomada do interesse, pois os recursos didáticos podem promover interação, proporcionar inclusão, motivar os alunos e proporcionar aprendizagem significativa (Tarouco et al., 2004).

Para o docente, estes mecanismos inovadores facilitam o seu trabalho e mudam o seu papel dentro da sala de aula que deixa de ser um indivíduo repassador de conhecimento, e se torna um mediador entre o aluno e as informações. Klein et al. (2005) também afirmam que oficinas pedagógicas podem funcionar como "aperfeiçoadores" do profissional da educação, atuando como um prolongamento da sua formação inicial.

Dessa forma, é necessário investir na formação inicial e continuada do professor, para que o mesmo seja capaz de desconstruir conceitos e preconceitos. Deste modo, é possível torná-lo um ser mais consciente, crítico, participativo e comprometido em desenvolver uma sociedade democrática. (Nunes, et al., 2010)

A constituição federal de 1988 assegura que é dever do estado à educação plena de todos, com atendimento educacional especializado aos portadores de necessidades especiais, preferencialmente na rede regular de ensino (BRASIL, 1998). Diante disso, é indispensável que se inclua estratégias que possam facilitar a compreensão dos discentes acerca dos conhecimentos abordados no contexto escolar, principalmente os assuntos de difícil assimilação, como é o caso de alguns conteúdos presentes nas ciências/biologia.

O ensino de ciências/biologia na maioria das vezes é apresentado por meio de elementos visuais, é isto acaba dificultando que o conhecimento chegue aos alunos com (DV), principalmente, pelo alto grau de abstrações. Desse modo, os recursos didáticos entram nesse contexto, a fim de garantir a estes alunos, um ensino de qualidade e prazeroso.

Por esse motivo, os recursos didáticos e Tecnologias assistivas assumem fundamental importância na educação de alunos com deficiência visual. Principalmente quando se trata do ensino de ciências, que por diversas vezes o uso de imagens, tais como fotos, tabelas, e até mesmo vídeos, contribuem para o 
entendimento dos alunos sobre o conteúdo que está sendo abordado. (SILVA et al., 2014).

As Tecnologias Assistivas (TA) são recursos e serviços utilizados por pessoas com deficiência, e tem como principal função facilitar o desenvolvimento das atividades e aumentar as capacidades funcionais, promovendo assim maior autonomia e a independência. Desta maneira, são utilizados como instrumentos para minimizar os problemas encontrados pelos indivíduos deficientes (Melo, Costa e Soares, 2006). Para Barros e Costa (2013), por meio da TA é possível buscar caminhos alternativos estimulando e potencializando a qualidade de cada aluno. Nesta perspectiva de uma escola ser considerada inclusiva, segundo Glat (2009, p.16) necessita que:

Para a escola tornar-se inclusiva, a escola precisa formar seus professores e equipe de gestão, e rever suas formas de interação vigentes entre todos os segmentos que compõem e que nela interferem. Precisa realimentar sua estrutura, organização, seu projeto politico-pedagógico seus recursos didáticos, metodologias e estratégias de ensino, bem como suas práticas avaliativas. Para acolher todos os alunos, a escola precisa, sobretudo, transformar suas intenções e escolhas curriculares, oferecendo um ensino diferenciado que favoreça o desenvolvimento e a inclusão social." (GLAT, 2009, p. 16)

Essa Inclusão tem base legal assente na Constituição federal de 1988 que assegura que é dever do estado à educação plena de todos, com atendimento educacional especializado aos portadores de necessidades especiais, preferencialmente na rede regular de ensino. (BRASIL, 1998).

Diante desse cenário, é indispensável que se inclua estratégias que possam facilitar a compreensão dos discentes (DV) acerca dos conhecimentos abordados no contexto escolar, principalmente os assuntos de difícil assimilação, devido ao grau de abstração, como é o caso de alguns conteúdos presentes nas ciências/biologia, por exemplo: células e organelas, explicar ao aluno cego, as diferenças de Retículo endoplasmático liso e retículo endoplasmático rugoso ou o Complexo de Golgi não é uma tarefa fácil levando em consideração a morfologia.

O processo de inclusão dos alunos (DV) abrange diversos fatores, como: a família, a estrutura da escola para receber esses alunos e também a qualificação dos professores para acolher este público. Nesse contexto, é necessário que haja a interação destes elementos, para que a educação inclusiva efetivamente ocorra. Segundo Wally, "as questões que envolvem o estímulo são de grande relevância para os educadores do século XXI, uma vez que, é algo que deve ser muito levado em consideração se quisermos visar à educação plena das crianças deficientes visuais.” (2011, p. 2).

Para além de teóricos que contribuem com essa discussão, temos os relatos dos próprios discentes do PARFOR, participantes do workshop que com base na sua experiência, assim se posicionam: "Estrutura logística, e uma política de fato inclusiva e as devidas informações 
necessárias. Capacitação dos profissionais da área, infraestrutura do espaço. Apoio da secretaria de educação da escola, dos pais. Recurso didáticos adequados” (relato sujeito de pesquisa).

É perceptível que um dos principais problemas em promover a educação inclusiva, seria a falta de políticas públicas. Neste contexto, percebe- se a importância de haver um trabalho em conjunto no ambiente escolar. Dessa forma, é necessário que os todos os membros do corpo docente junto, a coordenação e a secretaria de educação possuam um diálogo visando à melhoria da formação continuada para que aconteça efetivamente a educação inclusiva.

O capítulo V, artigo 58, da Lei das Diretrizes e Bases Nacionais, LDBEN, classifica educação especial "como modalidade de educação escolar, oferecida, preferencialmente, na rede regular de ensino, para educandos portadores de necessidades especiais”. A devida reverência estabelece nos devidos incisos a definição de acesso, condições, metodologias e recursos educativos para a efetiva implantação.

\section{O DOMINÓ INCLUSIVO: A APLICAÇÃO DO RECURSO DIDÁtICO E SUA IMPORTÂNCIA NO COTIDIANO ESCOLAR}

A presente pesquisa apresenta-se de caráter qualitativa, de Utilizando a pesquisa narrativa (Connely e Clandinim, 1995). Desta maneira, houve consultas bibliográficas sobre informações que norteiam à temática. $\mathrm{E}$ a partir disto, foram selecionados os tópicos que seriam abordados durante $\mathrm{o}$ workshop. Para subsidiar tal pesquisa, utilizou- se autores que retratam sobre o uso dos recursos didáticos, sobre a importância dos mesmos para tornar o ensino de qualidade e as questões referentes ao aluno deficiente visual, as quais destacaram os autores: Castoldi (2016); Souza (2007); Tarouco et al (2004); Glat (2009); Wally (2011).

O público alvo do workshop "recursos didáticos e inclusivos para o ensino de meio ambiente" foram os alunos do PARFOR, do curso de ciências naturais-biologia da Universidade do Estado do Pará, participaram da pesquisa cerca de dezenove (19) acadêmicos deste curso. Por se tratar de uma turma do PARFOR, as aulas destes alunos acontecem no período de janeiro a fevereiro e junho a julho.

O workshop foi realizado na Universidade do Estado do Pará (UEPA), no Centro de Ciências Sociais e Educação (CCSE), no período de 8 a 10 de julho de 2016, no período da manhã e tarde, com atividades teórico-práticas e totalizando carga-horária de 20 horas. A seguir, as atividades realizadas durante a pesquisa. 
O PARFOR tem como objetivo formar professores atuantes na educação básica que ainda não possuem formação adequada exigida na Lei de Diretrizes e Bases (LDB) ${ }^{5}$. Dessa forma, este Plano é de fundamental importância para reorganizar a formação inicial dos professores da rede pública, e assim promover a qualidade no ensino.

A experiência compreendeu 3 fases, sendo que na primeira fase, foi solicitado que os acadêmicos respondessem a um questionário prévio, a fim de realizar um levantamento sobre as concepções acerca da temática. O questionário constituiu-se de cinco (05) questões. Estas serviram de subsídios para analisar as primeiras compreensões dos acadêmicos sobre o tema. As cinco (05) questões envolviam o uso dos recursos didáticos inclusivos no contexto escolar de modo a promover aprendizagem efetiva dos conceitos científicos.

Os tópicos abordados foram: ecologia e meio ambiente, a importância do ensino de meio ambiente, as dificuldades dos alunos com o tema meio ambiente, educação: "o direito de todos", as dificuldades em promover um ensino inclusivo, o aluno cego e de baixa visão no ensino regular, escola inclusiva e por fim, a importância dos recursos didáticos para o ensino de meio ambiente. Além disso, mostraram-se recursos didáticos, que possam ser utilizados nas aulas de ciências/biologia. No decorrer, deste momento os discentes eram instruídos a dialogarem sobre suas experiências e sua opinião sobre o assunto.

Neste momento, realizou-se uma atividade, a qual os alunos foram orientados a formarem duplas. Em cada dupla, um aluno era responsável por guiar e o outro era guiado a pegar bombons, que foram distribuídos dentro da sala de aula. Após isso, os ministrantes do workshop, solicitaram que os discentes expressassem as percepções deles sobre os obstáculos que eles enfrentaram durante a atividade. $\mathrm{O}$ objetivo principal desta atividade foi demonstrar as dificuldades que o deficiente visual enfrenta no cotidiano.

$\mathrm{Na}$ segunda fase construiu-se um recurso didático inclusivo, o qual denominou-se de "Dominó Inclusivo Sobre Meio Ambiente". A priori, foram feitas 28 peças de MDF, e após isso selecionamos imagens e conceitos

Figura 1- Alunas realizando a atividade

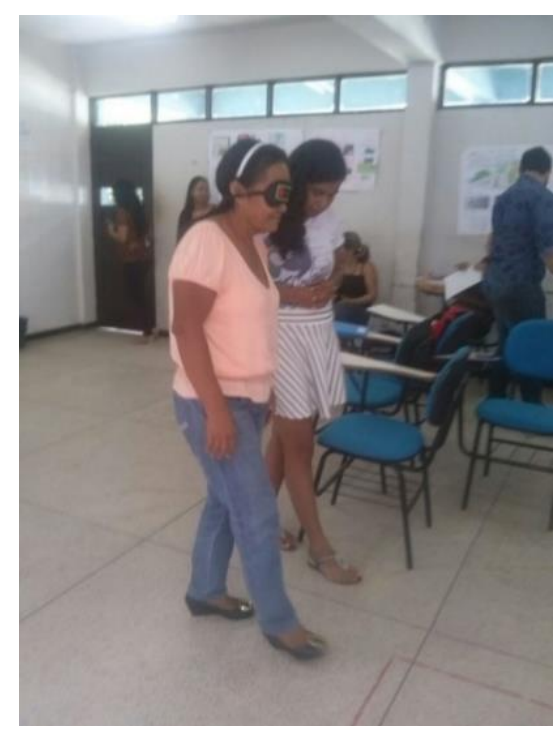

Fonte: Arquivo Pessoal, 2016

\footnotetext{
${ }^{5}$ Plano Nacional de Formação dos Professores.

Disponível:<http://www.aedi.ufpa.br/parfor/arquivos/legislacao/RELATORIOAVALIACAOPARFOR2012.pdf>
} 
referentes à temática meio ambiente. A partir disso, foram impressos em folha adesiva as 28 "faces" do jogo. Para tornar o jogo inclusivo aos deficientes visuais, utilizou-se a cola 3D para simular os pontos de alto relevo presentes no alfabeto Braille. Por isso, em uma "face" encontrava-se a imagem e o conceito e na outra "face" os conceitos escritos em Braille. O sistema Braille é o meio de leitura e escrita de pessoas cegas.

Figura 2- Peças em MDF com as imagens e conceito

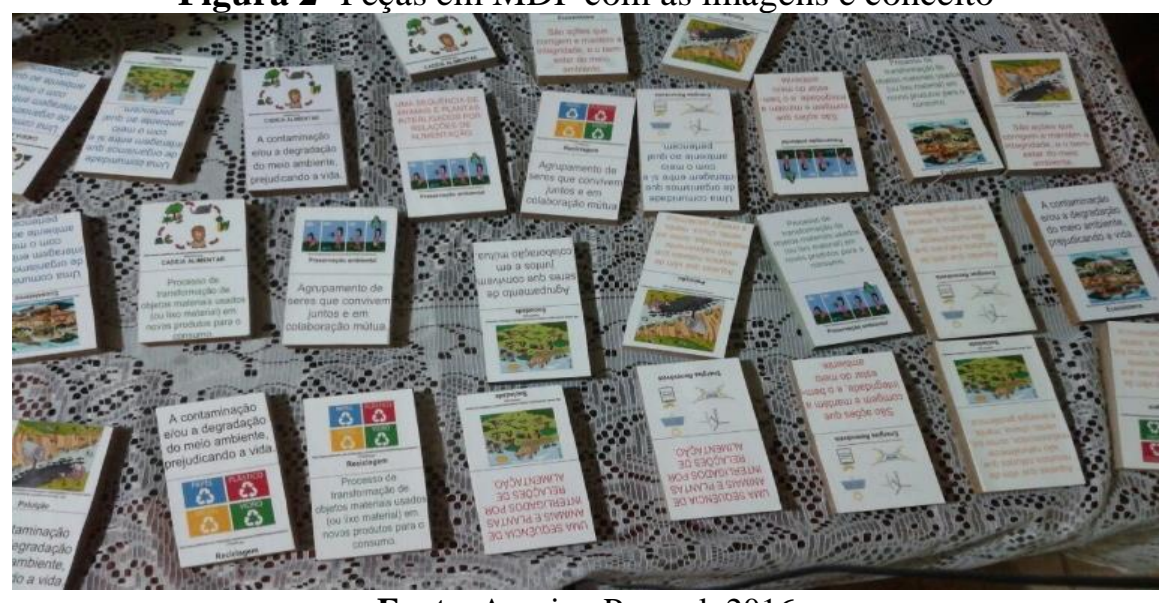

Fonte: Arquivo Pessoal, 2016

A Escrita em Braille foi realizada através do programa computacional Braille Fácil², a qual está disponível no site do Instituto Benjamim Constant, do Rio de Janeiro. A partir disto, digitou-se o termo referente ao conceito e o programa disponibilizou a imagem da palavra em Braille e com a cola 3D, construiu-se ponto a ponto, até formar o conceito.

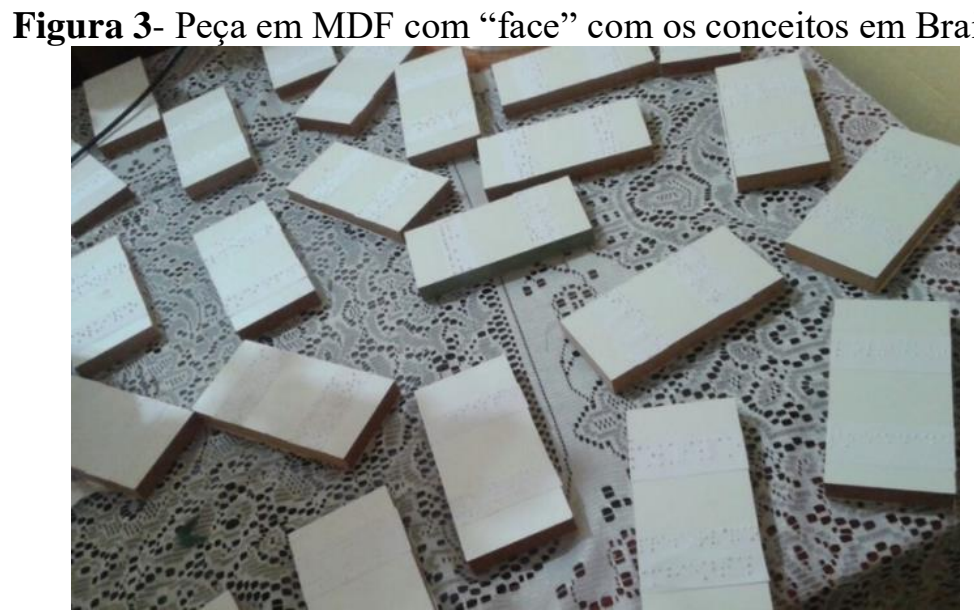

Fonte: Arquivo Pessoal, 2016.

${ }^{2}$ O Programa Braille Fácil é utilizado para transcrever textos para o Braille, facilitando assim a leitura pelos deficientes visuais, disponível para downloads em: <: http://www.ibc.gov.br/?itemid=387 
A terceira fase compreendeu as discussões sobre a temática, e culminou com a experiencia do material didático, onde a turma foi dividida em quatro (04) grupos, no qual cada grupo recebeu (07) peças do recurso didático construído. O objetivo do jogo é que se relacione a imagem ao conceito de cada tema, até que se acabem as peças contidas em cada grupo, como no jogo de dominó comum, o primeiro que terminar vence.

Por fim, depois das discussões realizadas, solicitou que os acadêmicos respondessem a um questionário final. Este possuía três (03) questões referentes aos benefícios que os recursos didáticos proporcionam ao ensino, sobre o auxílio que os recursos didáticos podem trazer ao ensino/aprendizagem dos alunos portadores de necessidades especiais e por último, se os acadêmicos utilizariam apresentados no workshop e pediu que os mesmos sugerissem outros recursos didáticos.

Dentre os relatos referentes aos questionamentos apresentados, alguns merecem destaque, a exemplo dos que dizem respeito a experiência/preparo para atuar com o público de alunos com deficiência, pois apesar de muitos professores já terem se deparado com este cenário de possuir alunos com necessidades especiais no ensino regular, a maioria dos participantes não se sente preparada para lidar com este desafio, por uma série de motivos. Cada necessidade especial possui suas diferenças muito bem aparentes, deste modo, cada necessidade carece de uma metodologia diferente e específica. É inviável ensinar um aluno com baixa visão da mesma maneira que se trabalha com um aluno com surdez.

Ainda que os participantes do workshop possuam experiência em sala de aula com outras disciplinas, o ensino de ciências requer de qualquer profissional noções de contextualização dos conteúdos com o cotidiano, visando a diminuição da abstração que a grade curricular de ciências possui, este fator aumenta a dificuldade dos professores em trabalhar com este tipo de aluno pois pessoas com necessidades especiais possuem um cotidiano totalmente diferente das pessoas que não possuem estas necessidades.

Durante o workshop, contamos com a participação de 20 alunos de PARFOR, sendo eles do sexo masculino e feminino, com idades declaradas entre 22 e 56 anos.

Tabela 1 - Distribuição do sexo dos alunos

\begin{tabular}{|c|c|}
\hline Sexo dos alunos & Número de alunos \\
\hline Masculino & 7 \\
\hline Feminino & 13 \\
\hline Total & $\mathbf{2 0}$ \\
\hline
\end{tabular}

Fonte: Dados da pesquisa, 2016. 


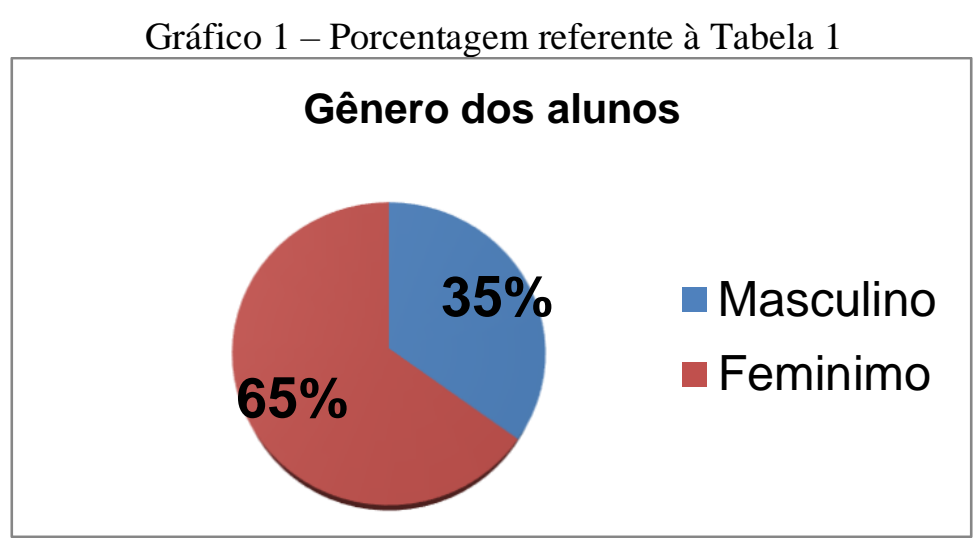

Fonte: Dados da pesquisa, 2016.

Gráfico 2 - Distribuição da Idade dos Alunos que Participaram do Workshop

\section{Idade dos alunos}

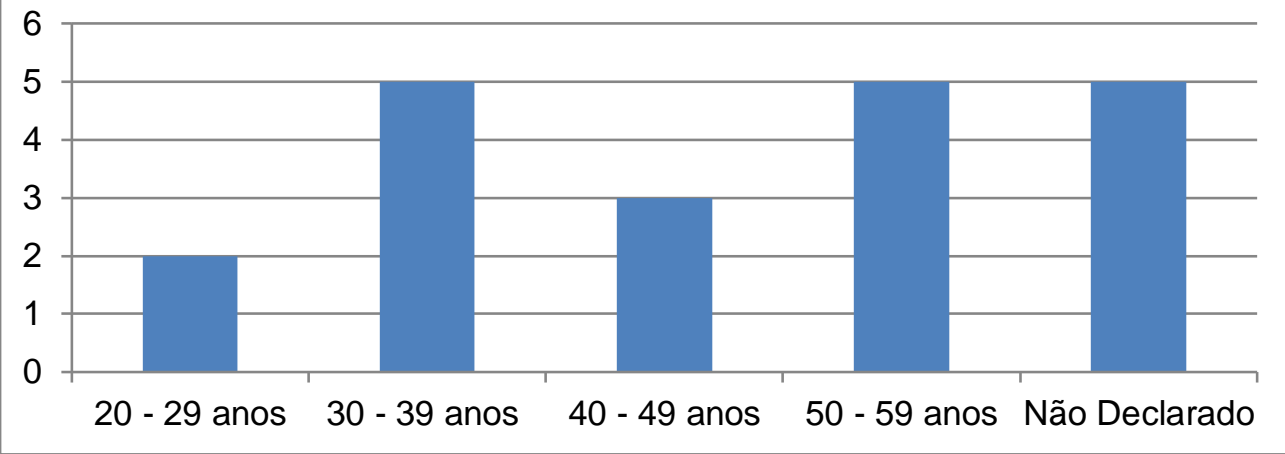

Fonte: Dados da pesquisa, 2016.

A análise de dados foi feita a partir da leitura dos questionários prévios e finais entregues aos alunos durante o workshop. Para facilitar a leitura e a interpretação dos resultados, serão apresentados gráficos, tabelas e/ou transcrições dos relatos dos alunos. Estes dados foram coletados entre Agosto e Outubro de 2016.

No Gráfico 3, a seguir mostra que o percentual de alunos que já utilizaram recursos didáticos em suas aulas, percebe-se um pouco mais da metade, tal realidade pode estar diretamente relacionada ao fato de que muitos graduandos estarem cursando a segunda graduação e a maioria já ter experiência docente.

Gráfico 3 - Percentual de alunos que utilizaram recursos Didático em sala de aula

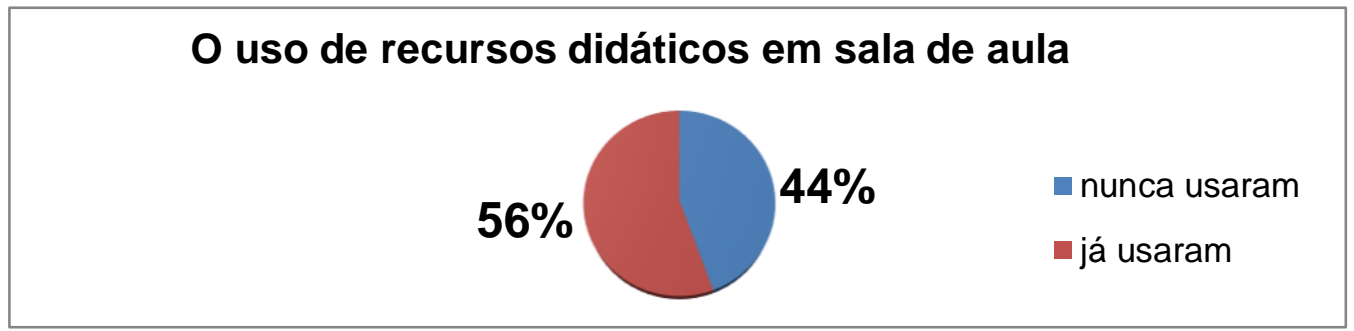

Fonte: Dados da pesquisa, 2016. 
Conforme apresentado no Gráfico 3, observa-se que 56\% dos graduandos já utilizaram recursos didáticos em sala de aula, enquanto $44 \%$ destes nunca buscaram aplicar outros métodos de ensino. Estes dados nos mostram que apesar de entramos em contato com o recurso didático durante a graduação, ainda sim quase metade dos professores não utilizam estes artifícios, ou por falta de interesse, de conhecimento sobre o tema ou por alegarem não terem condições de aplicá-los no seu ambiente de trabalho.

Outro fator importante que vale salientar é a falta de formação continuada e a possível carência na ênfase de metodologias alternativas da época da formação dos profissionais que participaram do workshop, alguns dos participantes já lecionam há cerca de 30 anos. Flóride \& Steinle (2014) afirmam que a formação continuada na escola é uma alternativa que melhora a qualidade do processo de ensino-aprendizagem e é feita a partir das necessidades e interesses da comunidade escolar.

As autoras demonstram que mesmo com professores já em atividade, a atualização e reflexão sobre as metodologias abordadas dentro do local de trabalho podem se tornar ainda mais valiosas, pois podem atender diretamente as dificuldades que a instituição possui. No segundo $\left(2^{\circ}\right)$ questionamento, pergunta- se a respeito da experiência dos professores com alunos portadores de necessidades especiais em sala de aula. O Gráfico 4, demonstra a proporções das respostas.

Gráfico 4 - Proporção de alunos do PARFOR que já trabalharam com PCD

\section{Você já trabalhou com os alunos portadores de necessidades especiais?}

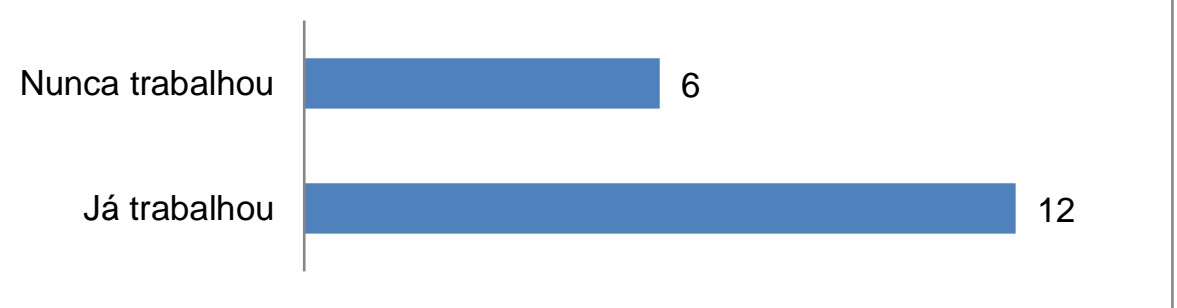

Fonte: Dados da pesquisa, 2016.

De acordo com o Gráfico 4, 12 dos presentes no workshop já trabalharam com alunos portadores de necessidades especiais no ambiente escolar. Enquanto 6 deles, afirmaram que nunca trabalharam com este público. Os que afirmam já terem trabalhado com os alunos portadores de necessidades especiais demonstram muita satisfação em observar o desenvolvimento intelectual destes alunos, entretanto expressam as dificuldades em trabalhar com este tipo de aluno.

Sim, sou especializada nesta área, então as experiências são muito, principalmente na área da surdez. A minha melhor experiência foi ver dois alunos passarem na UEPA, após trabalhar no ENEM como aplicadora de prova, os alunos foram classificados para estudar na UEPA, fiquei emocionada quando encontrei. (relato do graduando, pedagogo, sexo feminino). 
Sim, aluno com baixa visão, paralisia cerebral e deficiência intelectual, é um trabalho que exige dedicação e compromisso, porém, o resultado é gratificante. (relato do graduando, sexo feminino).

Pode-se perceber através dos relatos dos participantes que a baixa visão não é o único desafio deste tipo que um profissional pode enfrentar na sala de aula, deficiência intelectual e surdez, são outras necessidades especiais muito corriqueiras encontradas na rede pública de ensino.

No terceiro questionamento $\left(3^{\circ}\right)$ é perguntado se os acadêmicos se sentem preparados para lidar com alunos portadores de necessidades especiais. A Tabela 2 demonstra as respostas dos graduandos.

Tabela 2 - Respostas obtidas da $3^{\circ}$ pergunta do questionário prévio

\begin{tabular}{|c|c|}
\hline \multicolumn{2}{|c|}{$\begin{array}{c}\text { Você se sente preparado para lidar com os alunos } \\
\text { portadores de necessidades especiais no ensino regular? }\end{array}$} \\
\hline Sim & 3 \\
\hline Não & 15 \\
\hline \multicolumn{2}{|c|}{ Fonte: Dados da pesquisa, 2016. }
\end{tabular}

A partir da análise da Tabela 2, percebe-se que apesar de muitos graduandos possuírem experiência com alunos portadores de necessidades especiais em sala de aula (ver Gráfico 4), a grande maioria não se sente preparado para trabalhar com este tipo de aluno.

Não, minha resposta foi não no sentindo de não está preparado para todas as necessidades, apesar de que já trabalho com alguns alunos especiais. (relato do graduando, pedagoga, sexo feminino)

No âmbito da educação física sim, já dentro das ciências ainda sinto um pouco de dificuldade dependendo dos locais onde tenho que trabalhar. (relato do graduando, educador físico, sexo masculino)

Apesar de muitos professores já terem se deparado com este cenário de possuir alunos com necessidades especiais no ensino regular, a maioria dos participantes não se sente preparada para lidar com este desafio, por uma serie de motivos. Cada necessidade especial possui suas diferenças muito bem aparentes, deste modo, cada necessidade carece de uma metodologia diferente e específica, é inviável ensinar um aluno com baixa visão da mesma maneira que se trabalha com um aluno com surdez.

Ainda que os participantes do workshop possuam experiência em sala de aula com outras disciplinas, o ensino de ciências requer de qualquer profissional noções de contextualização dos conteúdos com o cotidiano, visando a diminuição da abstração que a grade curricular de ciências possui, este fator aumenta a dificuldade dos professores em trabalhar com este tipo de aluno pois 
pessoas com necessidades especiais possuem um cotidiano totalmente diferente das pessoas que não possuem estas necessidades.

No quarto $\left(4^{\circ}\right)$ questionamento, perguntou-se a respeito das dificuldades em promover a educação inclusiva no ensino regular. As respostas dos graduandos giraram em torno da falta de políticas públicas, que invistam em capacitação de profissionais e infraestrutura, tanto didática quanto espacial para a melhoria deste tipo de trabalho. A seguir, alguns relatos analisados a respeito do questionamento.

Estrutura logística, e uma política de fato inclusiva e as devidas informações necessárias. (relato do graduando, educador físico, sexo masculino).

Acredito que são muitos, principalmente, a falta de capacitação dos profissionais da área, infraestrutura do espaço, dentre outros. (relato do graduando, pedagoga, sexo feminino).

A falta de apoio da secretaria de educação da escola, dos pais, a falta de recurso didático para trabalhar com esses alunos com necessidades especiais. Dessa maneira, fica difícil incluir esses alunos no ensino regular. (relato do graduando, pedagoga, sexo feminino).

Entendo que não só a falta de preparo do professor, o meu ver a dedicação, o amor, o respeito para com o outro faz com que se busque o melhor, vá atrás desse conhecimento para dar um atendimento de qualidade a esses alunos. (relato do graduando, sexo feminino).

Um desafio muito importante é a mudança no sistema educacional dando mais formação de profissionais na área da educação especial com obrigatoriedade em todos os cursos de licenciatura. (relato do graduando, sexo masculino).

A meu ver precisa que nossos profissionais tenham a sensibilidade de que somos todos iguais e estes alunos precisam ser tratados com dignidade e respeito. (Relato do graduando, sexo feminino, 56 anos).

De acordo com o questionamento acima, é perceptível que um dos principais problemas em promover a educação inclusiva, seria a falta de políticas públicas. Neste contexto, percebe- se a importância de haver um trabalho em conjunto no ambiente escolar. Dessa forma, é necessário que os todos os membros do corpo docente junto, a coordenação e a secretaria de educação possuam um diálogo visando à melhoria da formação continuada para que aconteça efetivamente a educação inclusiva.

$\mathrm{Na}$ quinta $\left(5^{\circ}\right)$ e última pergunta do questionário prévio, perguntamos se o graduando já passou por situações de ficar com dificuldades para enxergar ou se possui algum familiar com este problema. Foram identificadas 8 pessoas que já passaram por este tipo de problema, enquanto 9 pessoas nunca passaram por este problema e não possuem familiares com este histórico.

Após a aplicação do questionário prévio e do workshop, foi utilizado o questionário final para avaliar as contribuições do workshop aos graduandos.

O primeiro $\left(1^{\circ}\right)$ questionamento solicitou os relatos dos discentes sobre os benefícios da utilização dos recursos didáticos para o ensino de meio ambiente por meio da pergunta "De que maneira os recursos didáticos podem trazer benefícios ao ensino de meio ambiente?”. De acordo com as respostas dos alunos: 
Fazer com que o aluno conheça as diversidades da ecologia de uma maneira lúdica, saber como preservar e valorizar o meio ambiente em que vive, através de brincadeiras e jogos como uma forma de conscientização e preservação do meio. (relato do graduando, sexo masculino)

Pode contribuir para fixar os conteúdos de maneira mais prazerosa, assim os alunos se sentirão mais motivados nas aulas. (relato do graduando, pedagoga, sexo feminino)

Proporcionando um aprendizado dinâmico e prazeroso. Dessa forma, poder amenizar as dificuldades que os educandos encontram no processo ensino/ aprendizagem. (relato do graduando, sexo feminino).

Estas afirmações se assemelham com a da autora Silva et. al. (2012) ao afirmar que "A utilização de recursos variados recursos didáticos é uma importante ferramenta para facilitar a aprendizagem e superar lacunas deixadas pelo ensino tradicional”.

A partir desta análise, podemos afirmar que metodologias alternativas como os recursos didáticos são eficazes para "encurtar" a distância que o aluno possui com o conhecimento dentro da educação básica e suas metodologias saturadas.

No segundo $\left(2^{\circ}\right)$ questionamento pergunta-se como os recursos didáticos podem auxiliar no processo de ensino/aprendizagem dos alunos portadores de necessidades especiais.

As respostas dos graduandos demonstram que os principais benefícios dos recursos neste caso seria o assunto apresentado de maneira mais prazerosa e a integração que traria ao cenário escolar para com os alunos.

De acordo com cada necessidade especial, os recursos didáticos possibilitam ao educando uma melhor compreensão e interação no processo ensino/aprendizagem. (relato do graduando, sexo feminino).

Permitindo a integração aos portadores de necessidades ao meio e convívio social para o ensino se torne mais prazeroso e interessante sem aulas vazias dos ensinos tradicionais e mecânicos. (relato do graduando, sexo masculino).

Os recursos didáticos são ferramentas que possibilitam tornar as aulas mais agradáveis e prazerosas, nesse sentindo os benefícios são inúmeros não só em relação aos conteúdos, como também para desenvolver as competências e habilidades desses alunos. (relato do graduando, sexo feminino).

Auxilia na aprendizagem, pois torna a aula e a sala um espaço inclusivo e socializado através de atividade motivadora. (relato do graduando, sexo feminino).

Esta é uma maneira de contribuir para o aprendizado que seja completo e significativo, nesse processo que e importante para a coleta de informações. (relato do graduando, sexo masculino).

No caso de alunos com cegueira e/ou baixa visão, por exemplo, os maiores empecilhos que eles enfrentam é a dificuldade de contato com o ambiente físico. Manoel et. al. (2006), discute essa temática afirmando que a falta de uma mediação adequada em relação ao ensino de um portador deste tipo de necessidade desmotiva o aluno, o distanciando dos conhecimentos oferecidos. Como relatam os participantes, os recursos apresentados resgatam o prazer de aprender e motivam os alunos a cada passo dado com o ensino. 
No terceiro $\left(3^{\circ}\right)$ questionamento foi perguntado aos acadêmicos se eles utilizariam os recursos didáticos apresentados no workshop. O Gráfico 5 demonstra a proporção de respostas deste questionamento.

Gráfico 5 - Respostas Obtidas da $3^{\circ}$ Pergunta do Questionário Final

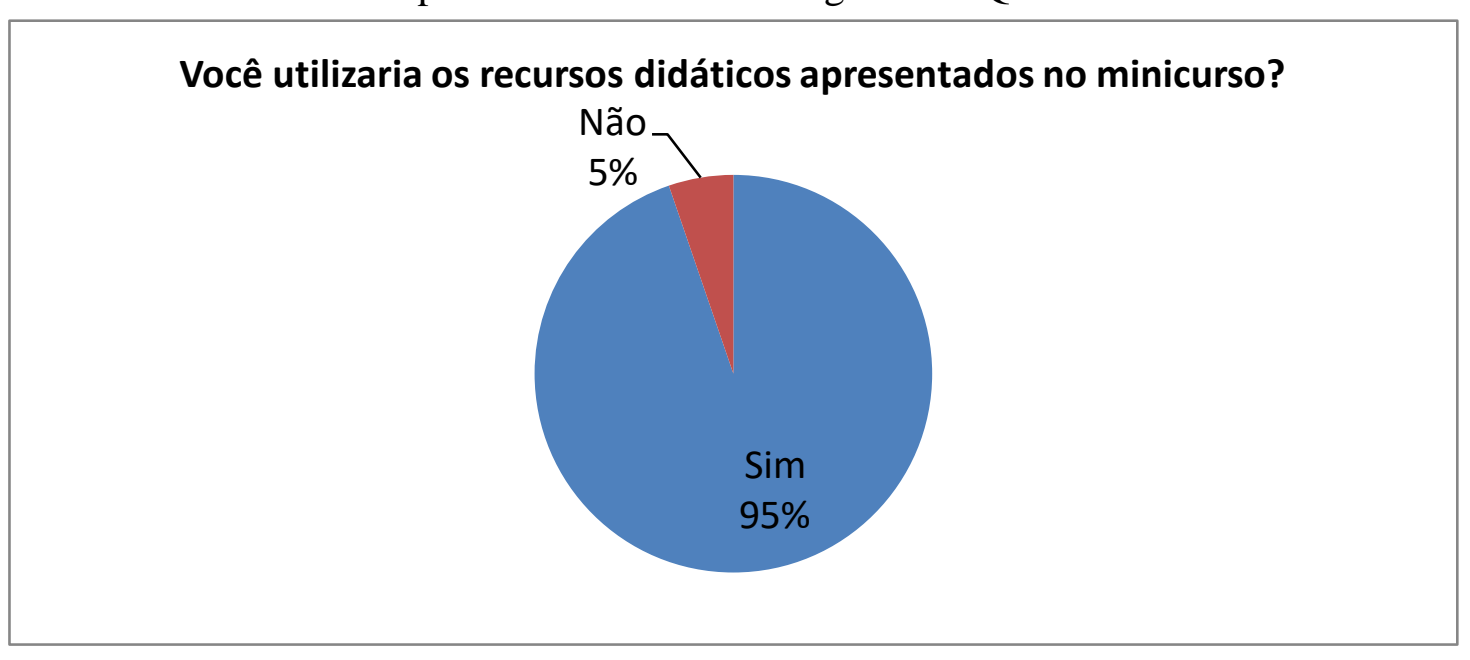

Fonte: Dados da pesquisa, 2016.

A partir do Gráfico 5 percebe-se que a grande maioria dos graduandos que participaram do workshop afirmaram que podem ou tem interesse em aplicar os recursos apresentados por acharem que estes, afetariam de maneira satisfatória tanto no ensino do professor quanto na aprendizagem do aluno

\section{CONCLUSÃO}

A experiência teve o intuito de investigar as concepções dos acadêmicos sobre a atuação com alunos deficiências visuais, possibilitando a estes debates necessários sobre as dificuldades em lidar/acolher os deficientes visuais, além disso, buscou-se mostrar os benefícios que os recursos didáticos podem trazer para o processo de ensino/aprendizagem dos alunos com tal necessidade e para aqueles ditos "normais".

É imprescindível que os docentes busquem metodologias que possam ser utilizadas com os diversos públicos presentes no ambiente escolar. Desta maneira, será possível promover a educação inclusiva no ensino regular. Além disso, é importante frisar que as licenciaturas devem se preocupar em realizar mais debates sobre o processo de educação inclusiva. No curso de licenciatura plena em ciências naturais- biologia há poucas disciplinas que discutem sobre este assunto. Dessa forma, a 
formação acaba sendo insuficiente neste aspecto e por este motivo dos acadêmicos apresentam dificuldades em realizar o ensino aos alunos deficientes visuais.

A aplicação do workshop possibilitou não só ao público presente, mas também as ministrantes um novo "olhar" para o processo de ensino/aprendizagem. Por se tratar de uma turma que está em atuação no ensino, durante o workshop alguns acadêmicos socializaram suas experiências, suas dificuldades e suas ideias para melhorar a qualidade do ensino dos alunos deficientes visuais.

Vale ressaltar que um dos grandes aliados em promover a educação inclusiva é o recurso didático, principalmente ao ensino de ciências/biologia, que na maioria das vezes é ministrado de forma visual. Além disso, o recurso didático pode proporcionar uma aula mais dinâmica, motivante e participativa. E isto foi perceptível na aplicação do recurso didático inclusivo, no decorrer da atividade os acadêmicos mostraram-se participativos e entusiasmados com o jogo.

Dessa forma, as ações, os debates, as experiências mostraram que é possível ter outras atitudes em relação ao ensino, que diante de todas as dificuldades, a educação inclusiva pode efetivamente acontecer no ensino regular.

\section{REFERÊNCIAS}

AULER. D. Enfoque ciência tecnologia sociedade: pressupostos para o contexto brasileiro. Ciência \& Ensino, vol. 1, número especial, novembro de 2007.

BARROS, V. F. A; COSTA, R. L. Educação Especial: a Tecnologia Assistiva no Atendimento Educacional Especializado. In: VIII International Conference on Engineering and Computer Education, Angola, 2013. Disponível em: http://s3.amazonaws. com/academia.edu.documents/42838749/Educao_Especial_a_Tecnologia_Assistiva_n20160219319 9Educacao_Especial_a_Tecnologia_Assistiva.pdf. Acesso em: 05 nov. 2016

BRASIL, Constituição da República Federativa do Brasil de 1988. Disponível em: <http:// www.planalto.gov.br/ccivil_03/Constituicao/Constituicao.htm>. Acesso em: 05 nov. 2015

BRASIL, Ministério da Educação e do Desporto. Parâmetros Curriculares Nacionais. Secretaria de Ensino Fundamental. Brasília: MEC/SEF, 1998.

FARIAS, L. de N.; Formação de Professores na Abordagem C-T-S: Um estudo no curso de Licenciatura Integrada em Educação em Ciências, Matemática e Linguagens da UFPA. Tese (doutorado) - Universidade Federl do Pará, IEMCI, Belém, 2017. 
FARIAS, Luciana de Nazaré; MIRANDA, Werventon dos Santos; FILHO, Silvio Carlos Ferreira Pereira. Fundamentos epistemológicos das relações CTS no ensino de ciências. Amazônia - Revista de Educação em Ciências e Matemáticas V.9 - nº 17. 2012, p.63-75.

GEHLEN, S.T, AUTH, M.A E AULER, D. Contribuições de Freire e Vygotsky no contexto de propostas curriculares para a Educação em Ciências. Revista Electrónica de Enseñanza de las Ciências. Vol. 7 Nº1 (2008).

GLAT, R. Educação Inclusiva: cultura e cotidiano escolar. Rio de Janeiro: 7 LETRAS, 2009.

GONÇALVES, T. V.O. Ensino de Ciências e Matemática e formação de professores: Marcas da diferença. Tese (doutorado) - Universidade Estadual de Campinas, Faculdade de Educação Campinas, SP, 2000.

KLEIN, T. A. S. Oficinas Pedagógicas: Uma Proposta Para A Formação Continuada De Professores De Biologia. In: Anais do V Encontro Nacional de Pesquisa em Educação em Ciências. Associação Brasileira de Pesquisa em Educação em Ciências Atas do V ENPEC. São Paulo. No 5. 2005 - ISSN 1809-5100. Disponível em: <http://www.nutes.ufrj.br/abrapec/ venpec/conteudo/artigos/1/pdf/p618.pdf >. Acesso em: 24 out. 2015.

KREBS, C. J. Ecology: the experimental analysis of distribution and abundance. New York: Harper International, 1972.

LIMA FILHO, F. S. A Importância Do Uso De Recursos Didáticos Alternativos No Ensino De Química: Uma Abordagem Sobre Novas Metodologias. ENCICLOPÉDIA BIOSFERA, Centro Científico Conhecer - Goiânia, vol.7, N.12; 2011 Pág. 166-173. Disponível em <http://www.conhecer.org.br/enciclop/conbras1/a\%20importancia.pdf>. Acesso em: 20 out. 2015

MALDANER, O.A, ZANON, L.B, Situação de estudo: uma organização do ensino que extrapola a formação disciplinar de ciências. in: Educação em Ciências- Produção de currículos e formação de professores, Ed. Ijuí, 2004.

MARIANI JUNIOR, R. O Estudo De Ecologia No Ensino Médio: Uma Proposta Metodológica Alternativa. In: [Dissertação de Mestrado]. Programa de Pós-Graduação em Ensino de Ciências e Matemática da Pontifícia Universidade Católica de Minas Gerais. Minas Gerais. 2008. Disponível em: <http://www.biblioteca.pucminas.br/teses/EnCiMat_MarianiJuniorR_1.pdf>. Acesso em: 25 out. 2015.

MELO, M, A; COSTA, J. B. C.; SOARES, S. C. M. Acessibilidade: discurso e prática no cotidiano das bibliotecas. Campinas: Central Cesar Lattes, 2006. Disponível em: 
<http://eurydice.nied.unicamp.br/portais/todosnos/nied/todosnos/artigo. 1.pdf> Acesso em: 16 nov. 2016.

MENEZES, B. S.; MARTINS, F. R.; ARAÚJO, F. S. Montagem de comunidades: conceitos, domínio e estrutura teórica. 2017. Oecologia Australis, v. 20, n. 1, p. 1-17. 2016.

MONIZ DOS SANTOS, M.E.V. Desafios Pedagógicos para o Século XXI. Ed. Livros Horizonte, Lisboa, 1999.

NUNES, B. C. Propostas de atividades experimentais elaboradas por futuros professores de Química para alunos com deficiência visual. In: XV Encontro Nacional de Ensino de Química (XV ENEQ), 15., Brasília, 2010. Disponível em: http://www.sbq.org.br/eneq/ xv/resumos/R1092-1.pdf. Acesso em: 21 out. 2015.

PERONI, N.; HERNÁNDEZ, M. I. M. Ecologia De Populações E Comunidades. Florianópolis: CCB/EAD/UFSC, 2011.

SÃO PAULO (Estado) Secretaria da Educação. Coordenadoria de Estudos e Normas Pedagógicas 1992 - Proposta curricular para o ensino de biologia $2^{\text {o }}$ grau. $3^{\text {a }}$ ed. São Paulo: SE/CENP. 64p.

SILVA, T. S.; LANDIM, M. F.; E SOUZA, V. R. M. A utilização de recursos didáticos no processo de ensino e aprendizagem de ciências de alunos com deficiência visual. Revista Electrónica de Enseñanza de las Ciencias Vol. 13, $\mathrm{N}^{\mathrm{o}}$ 1, 32-47 (2014). Disponível em: http://www.docenciauniversitaria.org/volumenes/volumen13/REEC_13_1_3_ex710.pdf. Acesso em: 25 out. 2015.

SOUZA, S. E. O Uso De Recursos Didáticos No Ensino Escolar. In: I Encontro de Pesquisa em Educação, IV Jornada de Prática de Ensino, XIII Semana de Pedagogia da UEM. 11(Supl.2):110-4. Paraná: ArqMudi. 2007. Disponível em: <http://webmail.dma.ufv.br/ downloads/MAT\%20103/2014-II/Rec\%20didaticos\%20-\%20MAT\%20103\%20-\%202014-II.pdf>. Acesso em: 24 out. 2015.

TAROUCO, L. M. R. Jogos Educacionais. Porto Alegre. 2004. Disponível em: http://www.cinted.ufrgs.br/ciclo3/af/30-jogoseducacionais.pdf. Acesso em: 23 out. 2015.

WALLY, P. O estímulo enquanto um fator que contribui para a aprendizagem do deficiente visual. Udesc em ação, Universidade do Estado de Santa Catarina. v.5, n.1, p:2, 2011. Disponível em: <http://revistas.udesc.br/index.php/udescemacao/article/view/2243/pdf_ 77>. Acesso: 20 de out 2015. 